\title{
Rota dos Nativos sob a perspectiva do turismo sustentável: estudo em comunidades de Nísia Floresta (RN)
}

\section{Rota dos Nativos under the sustainable tourism: perspective in communities of Nísia Floresta (RN, Brazil)}

Sueli Aparecida Moreira, Ingrid Rosalina da Silva, Camila Kayssa Targino Dutra, Silvânia Melo da Cunha, Gilberto Correia dos Santos, Bruno Ferreira Nunes Sobrinho, Guilherme Bridi

\begin{abstract}
RESUMO: Rota dos Nativos é um roteiro turístico localizado no Município de Nísia Floresta, litoral sul do Rio Grande do Norte, que abrange sete lagoas. Portanto, o objetivo do estudo envolveu caracterizar a rota das lagoas em Nísia Floresta para analisar o impacto das práticas excursionistas sobre os recursos hídricos. A pesquisa é de abordagem qualitativa através de observação participante no contexto das lagoas. Adicionalmente, empregouse roteiro temático em entrevistas com representantes locais. Constatou-se que o turismo sustentável pode ser adotado, considerando que as lagoas precisam ser conservadas, priorizando as comunidades. $O$ turismo sustentável combinado às ações de Educação Ambiental poderá trazer benefícios para o desenvolvimento regional.
\end{abstract}

PALAVRAS-CHAVE: Turismo Lacustre; Excursionismo; Turismo de Um Dia; Educação Turística.

ABSTRACT: Rota dos Nativos is a tourist itinerary located in the Municipality of Nísia Floresta, south coast of Rio Grande do Norte, which includes seven lagoons. Therefore, the objective of study involved characterizing the lagoon route in Nísia Floresta to analyze the impact of excursionist practices on water resources. The research has a qualitative approach through participant observation in the context of the lagoons. Additionally, thematic script was used in interviews with local representatives. It was found that sustainable tourism can be adopted, considering that the lagoons need to be conserved, giving priority to communities. Sustainable tourism combined with Environmental Education actions can bring benefits to regional development.

KEYWORDS: Lake Tourism; Excursionism; Day Tourism; Tourism Education. 


\section{Introdução}

A importância da água doce permitiu a organização social e a evolução humana. De acordo com Faber (2011), com o domínio da terra fértil, os pequenos grupamentos nômades optaram por estabelecer morada fixa às margens de rios vastos e ricos de recursos. A água doce foi o meio fértil para a agricultura e a sedentarização do homem na pré-história. O solo rico e a abundância de água foram primordiais para as grandes civilizações (FABER, 2011).

Ribeiro e Rolim (2017) destacam que a superfície do planeta Terra contém cerca de $71 \%$ de água em estado líquido e desse número, apenas $3 \%$ correspondem a água doce. Segundo os autores, todo o restante é de água salgada, no entanto, a água com potencial de utilização pelos seres humanos é a doce, pois a salgada contém minerais e sais impróprios à saúde humana. A água é o elemento inorgânico mais abundante na terra. Segundo Sperling (2005), a água é um dos principais componentes dos seres vivos chegando até a constituir $98 \%$ de organismos aquáticos.

Assim, a água doce é de suma importância para manutenção da vida no planeta Terra, ela está, intrinsecamente, ligada à saúde e à dignidade da pessoa humana, é um recurso essencial (RIBEIRO; ROLIM, 2017). De igual modo, Bacci e Pataca (2008) destacam a importância da água, pois na sociedade atual a água passou a ser vista como recurso hídrico e não mais como um bem natural, disponível para a existência humana e das demais espécies. Passou-se a usá-la indiscriminadamente, encontrando sempre novos usos, todavia, sem avaliar as consequências ambientais em relação à quantidade e qualidade da água.

No contexto de uso da água doce para além das necessidades biológicas do ser humano, Ferreira, Lopes e Araújo (2012) destacam que um dos principais atrativos para os turistas que buscam diversão e descanso são as reservas de água, sejam elas naturais ou artificiais. E nesse caso, citam-se as praias, lagoas, rios, barragens, balneários, cachoeiras, entre outros. Por outro lado, o crescente uso das lagoas para atividade turística, sem qualquer planejamento, coloca em risco esses ecossistemas, comprometendo a sua conservação.

É iminente a necessidade de gestão pública em elaborar um zoneamento para as lagoas, delimitando áreas prioritárias para conservação e áreas destinadas à atividade turística, de veraneio e comércio (LANZER et. al., 2013). Os autores verificaram que o uso indevido das lagoas com alterações que causam danos à vegetação e à fauna, somados às construções irregulares, resíduos dispostos incorretamente, pesca, poluição sonora e outros fatores comprometem as fontes de água doce que abastecem os habitantes da região costeira do Rio Grande do Sul (LANZER et. al., 2013).

Recentemente, estudo realizado por Rudzewicz et al. (2011) sobre os impactos do turismo e de outros usos em 30 lagoas ao longo do litoral norte, médio e sul do Rio Grande do Sul mostraram a devastação dos ecossistemas terrestres e o mau uso dos recursos hídricos naquela região. 
O estudo salientou a poluição das lagoas, a redução do volume de água durante o período de irrigação do cultivo de arroz, a contaminação das águas superficiais e subterrâneas, pela aplicação de pesticidas e fertilizantes no meio rural, facilitada pela alta permeabilidade dos solos arenosos (RUDZEWICZ et. al., 2011).

Na região Nordeste, destaca-se o município de Nísia Floresta, com abundância de água doce, localizado no estado do Rio Grande do Norte e faz parte do litoral sul potiguar. O município ganhou esse nome em homenagem à Dionísia Gonçalves Pinto, famosa pelo pseudônimo de Nísia Floresta, pioneira escritora e defensora da igualdade de direitos sociais entre gêneros, especificamente na luta pelo direito à educação por parte de meninas.

Nessa região, rica em mananciais de água doce, localiza-se boa parcela da população local, que se mantém a partir dos recursos advindos das lagoas e da terra. Naquela paisagem, qualquer alteração, mesmo que mínima, sem o devido planejamento, pode gerar consequências irreversíveis para a sociedade e para o meio ambiente. Nísia Floresta possui também uma das mais belas paisagens do litoral potiguar banhado pelo oceano atlântico, cujas praias caracterizam-se por falésias. Em seu interior ocorrem inúmeras lagoas, muitas delas pouco inclusas no planejamento turístico e cuja visitação poderia promover o desenvolvimento local.

Nesse contexto, cita-se a "A Rota dos Nativos", que é uma apropriação turística do ambiente lacustre para finalidades excursionistas e de lazer de um dia. A rota que teve início de modo experimental em 2016, atualmente percorre sete lagoas do município de Nísia Floresta em divisa com o município São José de Mipibu, ambos pertencentes ao estado do Rio Grande do Norte.

A Rota dos Nativos caracteriza-se pelo turismo lacustre recreativo de um dia, o turismo lacustre ou turismo nas lagoas. O turismo é considerado um fenômeno social, contemporâneo, complexo que pressupõe uma descontinuidade espaço-temporal, uma quebra com o cotidiano e que tem no espaço seu principal objeto de consumo (ARRUDA, 2010). Contudo, o principal ponto a considerar em termos de preservação ambiental diz respeito aos mananciais de água doce. O excursionismo e turismo de um dia em lagoas demandam um planejamento adequado e controlado do acesso às águas.

O excursionismo é uma prática social entendida aqui, como uma modalidade turística que corresponde, predominantemente, às classes sociais menos favorecidas e que diante de seu baixo poder de consumo, utiliza-se de alternativas criativas e de menores custos para ter direito a um dia de lazer em áreas de atratividades turísticas (ARRUDA, 2010). Na região Nordeste, trata-se de um fenômeno social comum que normalmente ocorre em dias de domingo e/ou feriados, dada a disponibilidade de tempo livre dos excursionistas, em sua maioria o perfil de trabalhadores que fazem uma viagem de poucas horas em direção às áreas de praias, lagoas, rios, balneários, levando comida, bebida, churrasqueira, carvão, guarda-sol, cadeiras entre outros itens que caracterizam os farofeiros. 
$\mathrm{Na}$ pesquisa realizada por Arruda (2010), constatou-se que é perceptível o impacto ambiental na região das lagoas, sobretudo, pelo amontoado de lixo, cercas e muros da comunidade local, um dos principais impactos ambientais relatados pelo autor. Nísia Floresta e municípios vizinhos definem a paisagem ideal para a atividade turística, portanto, é de suma importância estabelecer prioridades no planejamento do uso sustentável de recursos hídricos, prevenindo a contaminação do meio, mantendo a qualidade adequada para o consumo vital humano e, particularmente, da comunidade local.

Diante da importância das reservas de água doce tanto para as comunidades circunvizinhas às lagoas, quanto para a população que pratica o turismo lacustre de um dia, objetiva-se com esta pesquisa, caracterizar a Rota dos Nativos no município de Nísia Floresta para avaliar o impacto ambiental das práticas excursionistas sobre os recursos hídricos.

\section{Referencial Teórico}

\section{Roteiros Turísticos Ecológicos e/ou na Natureza}

Há muitas definições para o termo roteiro turístico, segundo o Ministério do Turismo, roteiro turístico é "[...] caracterizado por um ou mais elementos que the conferem identidade, definido e estruturado para fins de planejamento, gestão, promoção e comercialização turística" (BRASIL, 2007, p. 28).

O roteiro turístico consiste em uma organização e planejamento prévios de certo itinerário; é um plano/descrição de viagem, que contém os locais a serem visitados, o tempo de permanência etc. $O$ roteiro turístico pode ser feito a partir das segmentações existentes dentro de um destino turístico. Segmentar um destino significa agregar suas características particulares semelhantes. Há roteiros turísticos voltados ao turismo gastronômico, histórico-cultural, de sol e mar, ecoturismo e/ou de aventura, entre muitos outros. Os roteiros turísticos, segundo Tavares (2002, p. 20) "[...] podem ser uma das importantes maneiras de contextualizar atrativos e aumentar seu potencial de atratividade, o que pode dinamizar o potencial de atração turística da localidade".

O Ministério do Turismo afirma ainda que:

Roteirizar é uma forma de organizar e integrar a oferta turística do País, gerando produtos rentáveis e comercialmente viáveis. A roteirização é voltada para a construção de parcerias e promove a integração, o comprometimento, o adensamento de negócios, o resgate e a preservação dos valores socioculturais e ambientais da região (BRASIL, 2007, p. 26).

No município em questão, além do turismo de lazer praticado pelos turistas convencionais, existe a prática do turismo de aventura, ecológico e 
pedagógico. O roteiro é um percurso misto adaptado ao perfil do turista e a vivência que procura.

De igual modo, é notória a preocupação com os impactos que a atividade turística pode ocasionar ao meio geográfico ou espaço histórico, em pequena ou em grande escala. Emissão de gases poluentes por grandes indústrias nas proximidades podem provocar alterações profundas na paisagem. Mudanças no modo de vida de comunidades anfitriãs, bem como a apreensão contínua causada pelos surtos epidêmicos, novas doenças ou mesmo uma mutação podem ser decorrentes da movimentação turística. Dessa forma, são listados numerosos impactos ambientais gerados pelo turismo, por isso a necessidade de monitoramento constante (DIAS, 2005).

Neste aspecto, Kuhnen (2009), afirma que os problemas ambientais colocam questões a serem analisadas tendo em vista a relação sociedade/pessoa-natureza e essa relação é intrínseca aos eventos (emergências e desastres), bem como a questão da sustentabilidade planetária e os modelos de desenvolvimento adotados em nossa sociedade deveriam estar na ordem do dia. E assim, a presença de acontecimentos qualificados como catástrofes, desastres naturais ou industriais colocam no centro do debate as relações estabelecidas entre a sociedade e a natureza.

No contexto natureza e sociedade, um problema desencadeia outro, como um ciclo vicioso, caso não seja tratado e monitorado acarreta malefícios, muitas vezes irreparáveis, como a extinção de espécies endêmicas. Desse modo, o conceito de sustentabilidade tem estimulado o desenvolvimento econômico consciente, onde o lucro incessante não é prioridade, mas sim o enraizamento da cadeia estrutural do ecossistema onde o homem utiliza os recursos naturais de forma moderada e menos ofensiva ao meio possível. Nesta perspectiva, Leff (2009) aponta que:

O princípio da sustentabilidade surge no contexto da globalização como a marca limite e o sinal que reorienta 0 processo de civilização da humanidade. A crise ambiental veio questionar a racionalidade e os paradigmas teóricos que impulsionaram e legitimaram o crescimento econômico, negando a natureza. A sustentabilidade ecológica aparece assim como um critério normativo para a reconstrução da ordem econômica, como uma condição para a sobrevivência humana e um suporte para chegar a um desenvolvimento duradouro, questionando as próprias bases da produção (LEFF, 2009, p.15).

São consideráveis os aspectos que demonstram os danos acarretados no espaço ocupado pela atividade turística. Portanto, adverte-se maior cautela e estudo quando se envolve o manuseio do espaço turístico (DIAS, 2008). Nesse sentido, segundo Almeida (2013): 
A Política Nacional de Meio Ambiente, através da Lei 6.938/81 define poluição como sendo a degradação da qualidade ambiental decorrente de atividades que direta ou indiretamente prejudicam a saúde, a segurança e ao bemestar da população. Além do mais, dispõe sobre condições adversas às atividades sociais e econômicas que influenciam desfavoravelmente a biota, as condições estéticas e sanitárias do ambiente, inclusive sobre 0 lançamento de matérias ou energias em desacordo com os padrões ambientais estabelecidos (ALMEIDA, 2013, p.15).

Mediante ao aumento da poluição, organizações não governamentais e a própria sociedade vem pressionando o Estado por um posicionamento efetivo na proteção do meio ambiente e do direito de povos tradicionais e com isso movimentos sociais para tratar de questões ligadas à sustentabilidade vem ganhando notoriedade. Uma das maiores preocupações diz respeito ao futuro dos recursos hídricos em razão da disponibilidade. De acordo com Castro (2013, p.193) "A água doce participa com aproximadamente $2,5 \%$ do total de águas do planeta, e somente uma pequena fração dela está disponível para consumo humano".

As práticas excursionistas provocam grande impacto no meio ambiente e, particularmente, no saneamento básico. Sperling (2005) alerta sobre o impacto de eventos como excursões que geram grande deslocamento turístico para uma localidade específica, ocasionando sobrecarga no sistema de esgoto local. Segundo o mesmo autor, em época de alta estação e feriados prolongados, o aumento da população acarreta danos sérios, principalmente no sistema hídrico, com o descarte inadequado de resíduos e dejetos. O referido autor defende, ainda, a instalação de pesquisas aprofundadas para a definição do grau de impacto previamente ocasionado.

Em pesquisa a respeito dos impactos decorrentes da atividade turística, Molina (2003) constatou que, logo após a consumação do produto/destino, ou seja, após a alta estação ou término de feriados realizase um balanço do volume de resíduos versus rendimento econômico, e essa etapa também é designada por Sperling (2005) como "pós-turismo". Essa receptividade desenfreada gera desgaste ao meio ambiente, que requer, portanto, planejamento estratégico para descentralizar o turismo, diversificar os destinos, estabelecer limites de capacidade de carga, bem como regular acesso aos ambientes vulneráveis e ou patrimônios naturais.

Em relação ao suprimento de água para necessidades humanas vitais constatou-se que, embora o acesso a esse recurso seja um direito básico da humanidade, assegurado pela União das Nações Unidas - ONU, são alarmantes as falhas no sistema de abastecimento e tratamento de água no mundo, de acordo com o Centro de Informações das Nações Unidas do Rio de Janeiro - (UNIC, 2010). A esse respeito: 
Quase 900 milhões de pessoas no mundo não têm acesso à água potável e mais de 2,6 bilhões de pessoas não têm acesso a saneamento básico. Estudos também indicam que cerca de 1,5 milhão de crianças menores de cinco anos morrem a cada ano e 443 milhões de dias letivos são perdidos por causa de doenças relacionadas à água e ao saneamento (UNIC, 2010, p.1).

A situação de saneamento da população brasileira também é grave, pois mais de $50 \%$ ainda não tem esgoto coletado em suas casas e cerca de 35 milhões de pessoas não têm acesso à água tratada no país, de acordo com dados do Sistema Nacional de Informações sobre Saneamento - SNIS de 2015 (BRASIL, 2017).

A qualidade da água é uma preocupação global tratada na Declaração de Dublin, na Agenda 21, nos Objetivos de Desenvolvimento Sustentável (ODS) da Agenda 2030, e, em âmbito nacional, na Constituição Federal de 1988 e na Lei no 9.433 de 08 de janeiro de 1997, que instituiu a Política Nacional dos Recursos Hídricos - PNRH. A declaração de Dublin é produto da Conferência Internacional sobre Água e Meio Ambiente, realizada pela ONU em janeiro de 1992, constituindo-se em uma preparação para a RIO-92, seus fundamentos inspiraram o legislador constituinte na elaboração da PNRH (AMADO, 2016).

A temática das águas foi tratada no Capítulo 18 da Agenda 21, tendo como objetivo geral:

[...] assegurar a oferta de água de boa qualidade para todos os habitantes, mantendo as funções hidrológicas, biológicas e químicas dos ecossistemas, adaptando as atividades do homem aos limites da natureza e lutando para combater as moléstias ligadas a água (MMA, 1992, item 18.2).

A Agenda 2030 estabelece 17 Objetivos de Desenvolvimento Sustentável (ODS) e 169 metas correspondentes, que orientarão os trabalhos das Nações Unidas e de países membros em direção ao desenvolvimento sustentável. O objetivo 6 consiste, por exemplo, em assegurar a disponibilidade e gestão sustentável da água e saneamento para todas e todos (ONUBR, 2015).

Atualmente, no Brasil, prevalece o entendimento de que a água é um bem público, inexistindo águas de propriedade particular no país, conforme os artigos 20, III, VI, VII, e 26, I, da Constituição Federal de 1988, as águas quando não forem bens da União serão dos Estados, e, por analogia, do Distrito Federal (AMADO, 2016). A Lei no 9433/1997 assevera que a água é um bem de domínio público, da União, Estados ou Distrito Federal. A natureza pública da água reveste-se de caráter inalienável, sendo permitida apenas a sua utilização. 
A sustentabilidade tem sido aceita, sem muita resistência, como uma vantagem competitiva na promoção/divulgação organizacional através dos selos de certificações ambientais. A sociedade, por sua vez, entende como algo permanente e duradouro para prevenir danos socioambientais decorrentes do modelo econômico capitalista. Contudo, Leff (2009), afirma que o desenvolvimento sustentável ocorre quando existe a presença de valores ou até mesmo o sentimento de pertencimento a uma cultura e lugar.

\section{Método}

O estudo sobre a Rota dos Nativos é de natureza qualitativa e contemplou o discurso de 11 atores sociais que vivem ou trabalham no entorno das seguintes lagoas: Lagoa do Carcará, Lagoa da Juventude, Lagoa do Ferreira, Lagoa de Alcaçuz, Lagoa do Arroz (Búzios), Lagoa do Urubu e a Lagoa de Arituba, na região do município de Nísia Floresta localizado no Rio Grande do Norte.

Segundo Dencker (2007), uma pesquisa se constitui através da paciente observação sobre uma realidade. É papel do pesquisador não apenas coletar dados pertinentes à realidade estudada, mas assegurar que a pesquisa promova inovações. Os dados contextuais foram obtidos através de observação participante, considerada uma abordagem que compreende:

O processo no qual um investigador estabelece um relacionamento multilateral e de prazo relativamente longo com uma associação humana na sua situação natural com o propósito de desenvolver um entendimento científico daquele grupo (MAY, 2001, p.177).

A observação participante permite interagir no contexto, obter o registro de detalhes que facilitam a compreensão de adversidades e desigualdades. Segundo Meksenas (2002) na observação participante, "o pesquisador deve evitar as conclusões e fazer apontamentos daquilo que considera relevante, o importante é captar e descrever o ponto de vista do outro desviando-se de pré-julgamentos".

Com a finalidade de entender como o turismo é articulado e afeta uma comunidade será adotada a perspectiva dos moradores de Nísia Floresta, como eles enxergam, desde a relação própria com o espaço, até o encontro e efeito desse contato por terceiros. Foi dada a preferência aos que residem mais próximos às lagoas, tendo em vista que por terem mais contato com elas terão inquietações mais complexas e legítimas. Os depoentes dependem das lagoas para o sustento.

Os depoentes foram escolhidos pelo princípio de indicação livre dos próprios moradores, conforme as visitas de acordo com o acervo de informações solicitadas durante cada entrevista. Em relação aos aspectos éticos, os dados foram coletados mediante a obtenção do Termo de consentimento livre e esclarecido - TCLE em obediência à Resolução do 
Conselho Nacional de Saúde - CNS 466 de 2012 do Ministério da Saúde MS para garantir o anonimato do entrevistado, e para o maior conforto do mesmo em falar livremente de suas inquietações.

\section{Resultados e Discussão}

\section{Perfil Sociodemográfico}

Foram entrevistados 11 membros, sendo oito deles representantes da comunidade, comerciantes e três guias turísticos que realizam a rota no circuito das lagoas. Os nomes foram substituídos por nomes fictícios, sendo cinco mulheres e três homens, com idade entre os 23 e 66 anos, pessoas que vivem e ou dependem do comércio que ocorre no entorno das lagoas. Dos entrevistados, cinco possuem escolaridade até o ensino médio, e três, concluíram ou estão cursando o ensino superior. Contabilizam-se seis nascidos e residentes em Nísia Floresta. Os dois que não são do município são provenientes de Natal e Macaíba, ambos localizados no estado do Rio Grande do Norte, e tem uma média de oito anos que vivem no município (Quadro 1).

Quadro 1: Perfil sociodemográfico dos depoentes.

Frame 1: Socio-demographic profile of the interviewees.

\begin{tabular}{|c|c|c|c|c|}
\hline Nome Fictício & Gênero & Idade & Escolaridade & Ocupação \\
\hline Paula & F & 23 & Ensino Superior & Estudante \\
\hline Alice & F & 26 & Ensino Médio & Autônoma \\
\hline Felipe & M & 27 & Ensino Superior & Estudante \\
\hline Claudia & F & 32 & Ensino Médio & Garçonete \\
\hline Vilma & F & 35 & Ensino Superior & Professora \\
\hline Ricardo & M & 43 & Ensino Médio & Comerciante \\
\hline Gabriela & F & 51 & Ensino Médio & Cozinheira \\
\hline Pedro & M & 66 & Fundamental & Autônomo \\
\hline Sândala & F & 26 & $\begin{array}{c}\text { Bacharel em } \\
\text { Turismo }\end{array}$ & Guia \\
\hline Wilson & M & 31 & $\begin{array}{c}\text { Bacharel em } \\
\text { Turismo }\end{array}$ & Guia \\
\hline Parise & F & 27 & Nível Técnico & Guia \\
\hline
\end{tabular}

Fonte: Elaborado pelos autores (2021).

Source: Elaborated by the authors (2021).

As migrações foram decorrentes da alta taxa de desemprego, custo de vida elevado, e impossibilidade de crescimento profissional. Influenciados pelos diálogos com familiares e conhecidos, migraram para Nísia Floresta em busca de melhores condições de vida, conforme relataram. Os nativos nunca deixaram suas casas com intenções de morar em outro lugar. Quanto à ocupação dos entrevistados: dois autônomos, dois que se declaram apenas estudantes, uma professora, um proprietário de restaurante, uma cozinheira, uma garçonete e três guias de Turismo.

Observa-se no teor dos depoimentos abaixo, a grande importância atribuída à água e divergências sobre a origem da água consumida na região: 
Sem ela não existiríamos, vejo a importância cada vez mais de se preservar ela (Paula, 23);

Acho que é de poço, água é um bem precioso (Alice, 26);

A água vem do sistema de abastecimento público. Eu enxergo como sendo uma fonte de vida fundamental para tudo que há na terra, sabendo que nosso corpo tem mais água do que sangue e o planeta tem mais água do que terra [...] (Felipe, 27);

Água é vida, importante pra tudo, tomar banho, lavar a roupa, beber, cozinhar. Tudo na vida precisa de água (Cláudia, 32);

Não sei ao certo qual a origem da água. água é nossa fonte de vida, sem ela não existiríamos (Vilma, 35);

Acho que a água é da lagoa de Boágua. É uma coisa muito útil para vida da gente, sem água não sobrevivemos (Gabriela, 51).

Uma das falas positivas, sobre a relação do homem com a água, parte da premissa de que o depoente vivenciou um período de estiagem forte, que pode explicar essa concepção genuína de uso da água, que se resume à disponibilidade e não à qualidade.

De acordo com Deen (2012) na carta capital, em âmbito internacional, a água faz parte dos Direitos Humanos Fundamentais, reconhecida desde 2010 pela Assembleia Geral da ONU e pelo Conselho de Direitos Humanos das Nações Unidas.

Vem de poço, quando falta a gente pega da lagoa mesmo, a gente ferve se for pra beber e para o resto tá de bom tamanho. Água é necessária para tudo. Apesar da água daqui não ser muito limpa, não dá pra achar muito ruim, tem canto aí que nem água tem direito (Pedro, 66).

\section{De "Caminho das Águas à Rota dos Nativos"}

A história da Rota dos Nativos começou quando bugueiros de Nísia Floresta levavam os turistas para passeios pelas trilhas da região. Com o passar do tempo uma associação alternativa (Lacustre Bonfim) investiu em realizar o trajeto em três lagoas vizinhas, depois de alguns meses, viu-se que seria viável ampliar um pouco mais esse trajeto. Então, outras quatro lagoas foram inseridas no roteiro turístico. De acordo com a guia Parise (27 anos), a "Rota dos Nativos começou a ser oferecida desde 2016 quando era conhecida como Caminho das Águas. Nos últimos 3 anos trocou de nome para Rota dos Nativos [...] a Rota existe desde o ano de 2016".

O circuito completo "Caminho das Águas" realiza paradas nas principais lagoas que compreendem: Lagoa Redonda, Lagoa de Arituba, Lagoa de Alcaçuz, Lagoa de Boágua, Lagoa de Ferreira Grande, Lagoa do Carcará (Figuras 1 e 2) e, por último, na Lagoa do Urubu, sendo a lagoa de Arituba (Figuras 3 e 4), e Lagoa de Alcaçuz (Figuras 5 e 6) com mais infraestrutura. 


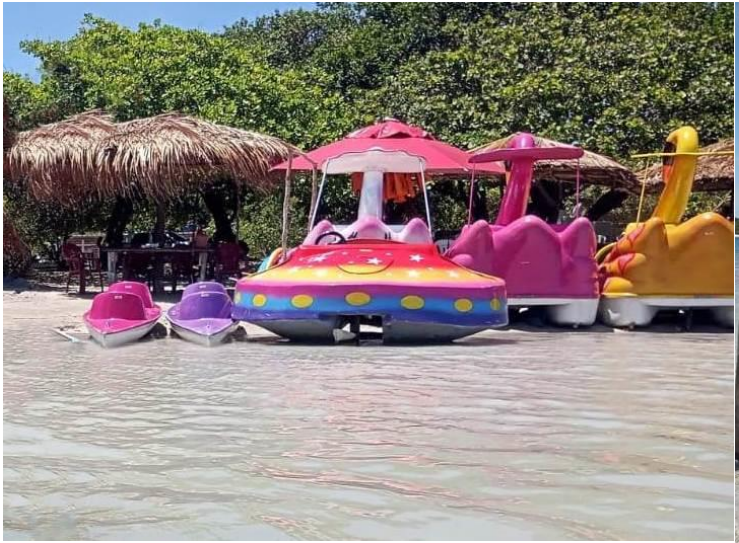

Figura 1: Lagoa do Carcará.

Figure 1: Carcará Lagoon.

Fonte: Elaborado pelos autores (2020). Source: Elaborated by the authors (2020).

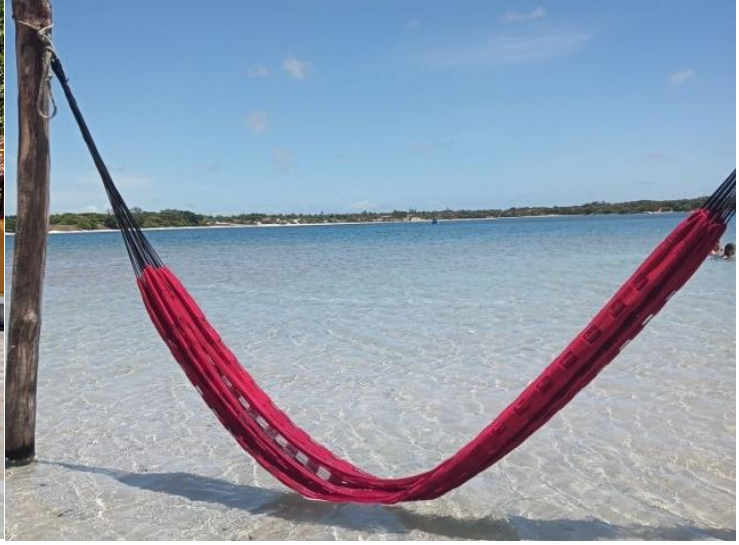

Figura 2: Lagoa do Carcará.

Figure 2: Carcará Lagoon.

Fonte: Elaborado pelos autores (2020). Source: Elaborated by the authors (2020).

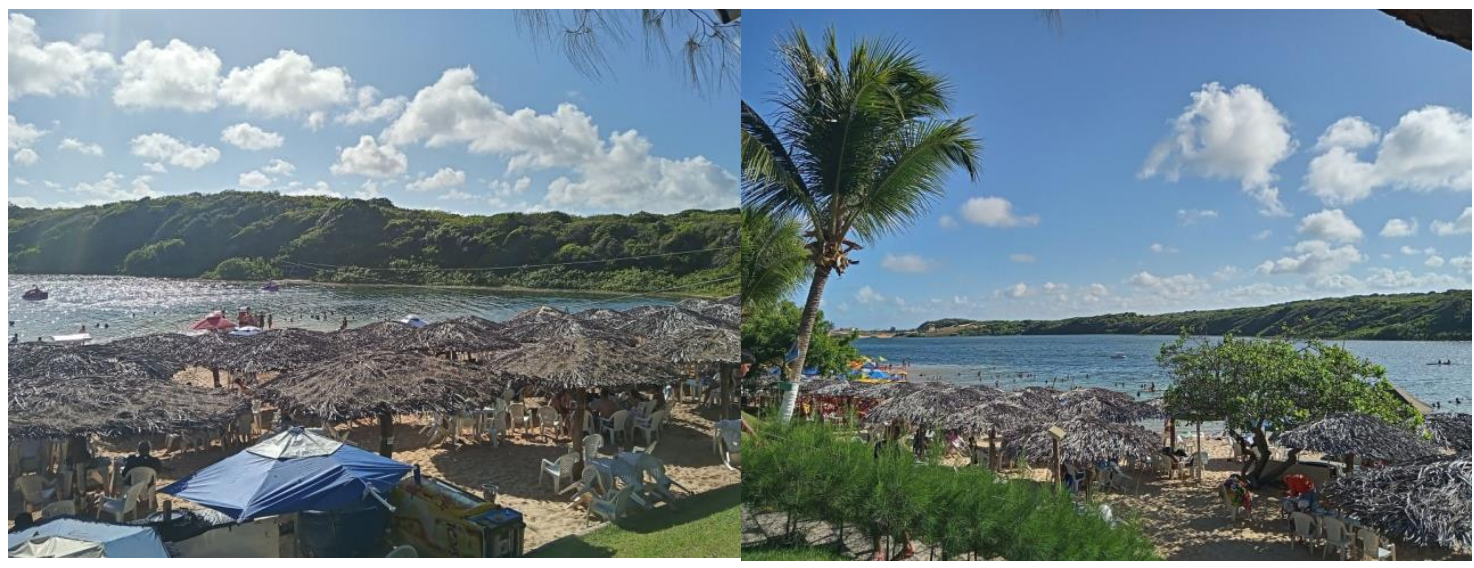

Figura 3: Lagoa de Arituba.

Figure 3: Arituba lagoon.

Fonte: Elaborado pelos autores (2020).

Figura 4: Lagoa de Arituba.

Figure 4: Arituba lagoon.

Source: Elaborated by the authors (2020).

Fonte: Elaborado pelos autores (2020).

Source: Elaborated by the authors (2020).

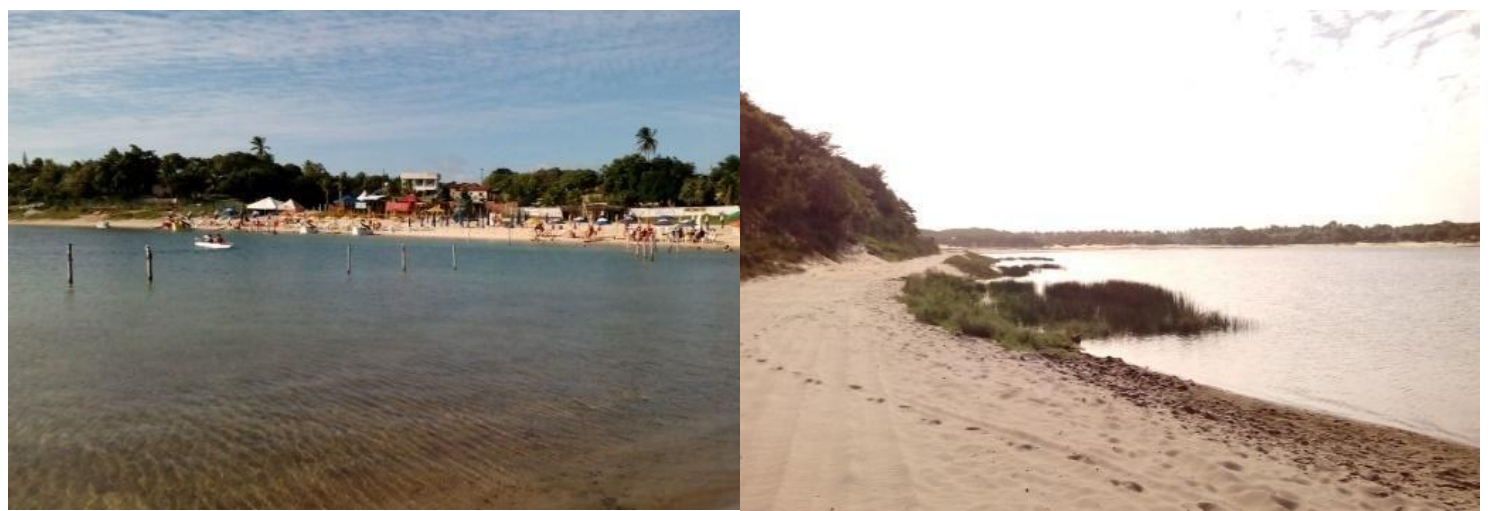

Figura 5: Lagoa de Alcaçuz.

Figure 5: Alcaçuz Lagoon.

Fonte: Elaborado pelos autores (2017). Source: Elaborated by the authors (2017).
Figura 6: Lagoa de Alcaçuz.

Figure 6: Alcaçuz Lagoon.

Fonte: Elaborado pelos autores (2017). Source: Elaborated by the authors (2017). 
Em relação à qualidade da água, constatou-se uma frustração por parte dos representantes da comunidade, tendo em vista que a qualidade ideal está muito longe de ser alcançada, essa apreensão revela a consciência de duas entrevistadas em relação ao uso desse bem essencial, conforme refletem os depoimentos a seguir:

A água vem de poço, mas sempre falta. Tem tempo que o poço fica que é só barro e não dá pra beber a água. É um sofrimento (Claudia, 32);

Apesar do descaso e do uso inconsciente, acredito que um dia todos irão notar que a mudança de simples hábitos faz toda a diferença (Vilma, 35).

Existe fundamento com a apreensão de que em algum momento a água em qualidade se torne um recurso ainda mais difícil de ser encontrado. São vários os poluentes que contribuem para tornar a água imprópria para consumo humano, como, por exemplo: o descarte incorreto do esgoto doméstico, poluição e os metais pesados. De acordo com Silva (2015), os metais pesados podem ser encontrados facilmente em concentrações pequenas, somados a outros elementos. Quando difundidos no meio ambiente são geralmente absorvidos pelos seres humanos, através de meios aquáticos e compostos da cadeia alimentar.

[...] corremos o sério risco de ficarmos sem ela em pouco tempo, já que existe pouca água doce no planeta terra (Paula, 23);

Sem dúvida nenhuma sempre foi o que nós deveríamos ter mais prezado, é uma tristeza que não seja assim, e acho que deve piorar do jeito que vai (Ricardo, 43).

Como consequência do consumo da água com qualidade questionável, afirmam os entrevistados, que eles podem estar colocando em risco suas próprias vidas, além de problemas com a presença de agentes contaminantes que causam doenças e complicam a saúde humana.

Em tempos de crise no abastecimento público da região é feito o uso da lagoa para suprir as necessidades básicas. O problema implica na discussão posta anteriormente, sobre a frequência da água não ser própria para o consumo, seja por conter resíduos que prejudicam a saúde, ou até mesmo pela falta de estudo e testes que comprovem a qualidade físicoquímica segura à saúde humana.

Pode-se evidenciar a indigência da lagoa enquanto complemento de um sustento, não apenas o recurso hídrico, mas todo o espaço, como a vegetação, e tudo que é articulado no comércio existente em volta. Os entrevistados atribuem a lagoa um espaço de apresentação e trabalho manual, como artesanato e a própria gastronomia. Um dos depoimentos 
atribuídos à lagoa é de Claudia (32 anos), ela afirma que sua família retira de lagoa parte de suas rendas para o seu sustento, através da pesca, ela consegue pagar suas contas, já que o lazer não é algo tão corriqueiro. Em seguida, Ricardo (43 anos) obtém da lagoa alimentos para usar em seu restaurante, bem como afirma a relevância da pesca para muitas famílias de Nísia Floresta. O depoimento de Pedro (66 anos) afirma a relevância da pesca para complemento da renda, como é possível observar nos depoimentos:

Trabalho nela [...] tem gente que vem pra cá para tomar banho e eu vivo dela, ela me dá trabalho [...] quando tem muito peixe eu vendo e o dinheiro que apuramos já é uma conta que ajuda para pagar (Claudia, 32);

[...] A lagoa serve para que eu consiga peixe fresquinho para os meus clientes. Dela tiro meu sustento. É importante lembrar que muita gente vive da lagoa e tira o sustento da família. (Ricardo, 43);

Nas horas vagas eu pesco. Faço um pouco de tudo para sobreviver (Pedro, 66).

Uma das primeiras coisas que se vem à mente quando se trata de lagoas é como fonte de lazer, é o momento em que a pessoa deixa suas responsabilidades de lado e aproveita um momento de puro desligamento das preocupações corriqueiras de uma rotina comum.

Segundo Dumazedier (1973), compreende-se o lazer como a diversidade de atividades com as quais uma pessoa pode manter um vínculo livre e um intuito de recreação, sendo assim, um voluntário momento de descontração. Para Gomes (2011) o lazer trata-se de uma necessidade humana e dimensão da cultura que constitui um campo de práticas sociais ludicamente vivenciadas pelos sujeitos, fazendo parte da vida cotidiana em todos os tempos, lugares e contextos.

As descrições que seguem abaixo representam aspectos do lazer, que é a disposição do tempo livre, conforme depreende-se dos depoimentos como a ida a lagoa nos finais de semana, com amigos e parentes.

Nos finais de semana costumo vir com a família e amigos para relaxar (Paula, 23);

Uso para me divertir com os amigos (Alice, 26);

Só para o lazer (Felipe, 27);

Quando tenho folga tomo um banho (Cláudia, 32);

Uso apenas nos fins de semana, geralmente com a família, para desopilar, quebrar um pouco a correria do cotidiano e renovar as energias para a semana (Vilma, 35). 
O depoimento de Vilma (35 anos) vai mais além, afirmando que essa fuga da rotina para a lagoa serve como pausa e lazer em contraste aos dias da semana. Ela ainda afirma que ao fazer isso, se mostra revigorada para recomeçar todo o ciclo novamente.

No que refere ao ambiente aquático, a água é responsável por manter boa parte das espécies aquáticas e até mesmo dos que vivem da pesca. Como evidenciado antes, existe uma forte cultura de pesca na região, seja para o consumo próprio ou para comercialização. A lagoa é a incorporação da pesca como um modo de sustento: "[...] meu marido pesca, muitas vezes já é o jantar" contou Cláudia, (32 anos).

O depoimento de uma estudante do curso de Biologia vislumbra a lagoa e a vegetação em volta, como uma oportunidade de exercitar os conhecimentos adquiridos na academia: "[...] uso para conhecer um pouco dos espécimes nativas, isso me ajuda a colocar em prática o que vejo em sala de aula" (Paula, 23).

Quando questionados sobre a preservação da lagoa, obteve-se dos entrevistados afirmações acerca da necessidade de um maior envolvimento do poder público nessa questão. É interessante ressaltar que o poder público é um dos principais responsáveis em assegurar que o meio ambiente se mantenha ecologicamente equilibrado e pelo bem-estar social, mas a própria comunidade pode tornar-se ativa nas mudanças.

A Constituição Federal de 1988 estabelece em seu artigo 225 que:

Todos têm direito ao meio ambiente ecologicamente equilibrado, bem de uso comum do povo e essencial à sadia qualidade de vida, impondo-se ao Poder Público e à coletividade o dever de defendê-lo e preservá-lo para as presentes e futuras gerações.

Uma das maneiras mais produtivas para alcançar o que a Constituição determina é a cultura da sustentabilidade, a inquietação e a cobrança em massa, como é afirmado pela Paula (23 anos): "Deve ter uma maior preocupação por parte do poder público em resolver os problemas que temos hoje".

A ideia de responsabilização social surge à medida que a comunidade se mostra inquieta, perante a degradação do espaço, contudo, são escassas as medidas reivindicatórias ou articulações para exigir melhorias do poder público. Depreende-se pelas falas, que a busca de soluções é atribuída a terceiros. Existe uma dependência em esperar 0 poder público tomar a frente da causa.

As pessoas deveriam se preocupar mais com o futuro daqui preservar. Não sujar, nossas praias e lagoas (Alice, 26); 
Deveria ser feito trabalho de conscientização coletiva, principalmente aos fins de semana que as lagoas recebem inúmeros ônibus com turistas (Vilma, 35);

Acho que deve ser investido em fiscalização e manutenção (Felipe, 27).

São necessárias políticas ativas que promovam a sustentabilidade do ecossistema em questão, para prevenir qualquer desgaste representativo e atípico, tanto por parte da comunidade, quanto pelos visitantes, conforme 0 depoimento de Felipe (27 anos). O depoimento de Ricardo (43 anos), somado ao de Pedro (66 anos), demonstra que a comunidade deveria buscar o controle da situação, diante dos problemas constatados. 0 resultado dessa participação poderia culminar na melhoria da relação com o meio ambiente: "Se cada um fizesse a sua parte, as coisas não seriam do jeito que são hoje. A consciência é o que mais importa" (Ricardo, 43); "Deviam fazer o saneamento" (Gabriela, 51); "O povo tem que parar de jogar lixo em todo canto" (Pedro, 66).

Como já mencionado em momentos anteriores deste artigo, os recursos hídricos são limitados, e por esse motivo devem ser pensados como extremamente relevantes para a sociedade. Tendo em vista a importância da água para o equilíbrio da vida na terra. Nesse contexto, os três depoimentos a seguir mostram o impacto ocasionado pelo turismo mal planejado:

Muita gente vem aqui e faz descarte de seus lixos, e isso prejudica principalmente a nós, os moradores (Paula, 23);

Tem muita gente que joga lixo, é errado, porque assim mata os peixes e a gente necessita deles [...] o povo tem que parar de sair jogando plástico pelos cantos. O certo é cada um juntar tudo e depois colocar num saquinho [...] a lagoa tem que ser cuidada, do mesmo jeito que dá a gente a gente tem que dar a ela (Claudia, 32);

Não despejar o esgoto nas lagoas (Gabriela, 51).

O registro de resíduos depositados na água e solo desqualifica a interpretação de hospitalidade para o turismo. O fato de ser despejado resíduo sólido direto em lagoas deveria gerar responsabilização por parte do poder público. Isso ocorre por falta de fiscalização, bem como pela ausência de políticas fortemente amparadas com apoio estratégico, como mencionado anteriormente, políticas públicas são necessárias para manter o espaço seguro da degradação. A participação de especialistas em estudos de consequência da degradação ambiental por parte do turismo deveria ser uma das maiores inquietações de gestores e governo. 


\section{Saneamento Básico e Coleta Seletiva}

Em publicação do Ministério do Meio Ambiente, o Programa de Regionalização do Turismo - Roteiros do Brasil, abordou importantes temáticas, como a relação do turismo e as comunidades: "o turismo tem, de fato, o potencial de colaborar com a proteção e a conservação do meio ambiente, e também com a consequente melhoria e manutenção da qualidade de vida das comunidades receptoras" (BRASIL, 2007, p.46).

De acordo ao documento há relevantes benefícios na atividade turística, dentre os quais se destacam: o aumento no investimento para conservação e manutenção do ambiente visitado; melhoria das condições ambientais do destino; conservação, preservação, proteção e recuperação dos ambientes naturais; sensibilização dos turistas para as questões ambientais etc. (BRASIL, 2007). Por outro lado, os impactos negativos são mais numerosos e rápidos, como exemplos: a ampliação da demanda pelos recursos naturais disponíveis; poluição em todas as suas formas, pela emissão de gases nocivos, o lançamento de óleo na água por lanchas, poluição sonora, dentre outros (BRASIL, 2007).

Durante observação junto às comunidades constatou-se dificuldades dos moradores próximos à lagoa, em relação ao saneamento básico e à coleta seletiva. Nesse contexto, de acordo com o Ministério de Meio Ambiente - MMA (2016), a coleta seletiva trata-se de uma seleção e divisão de resíduos, que tem como intuito tornar mais fácil a reciclagem, já que cada um tem composição diferente. Os municípios são obrigados a implantar a coleta seletiva sob a tutela da Política Nacional de Resíduos Sólidos.

Muito embora, quando indagados sobre o descarte do lixo doméstico, obtemos os seguintes depoimentos dos entrevistados: "O lixo é depositado em sumidouro (Gabriela, 51)"; "O carro do lixo passa e leva. Tem gente que passa coletando lata e plástico (Claudia, 32)".

O saneamento básico é uma questão extremamente delicada, não apenas no município, mas em todo o estado. Em decorrência da ausência de saneamento básico adequado, a população está suscetível à contaminação com resíduos sólidos. Nesse aspecto, o Programa de Regionalização do Turismo - Roteiros do Brasil, traz como impacto negativo da atividade turística:

A inexistência de saneamento básico, que tem como consequência a descarga de esgoto diretamente na água. Além do impacto na biodiversidade (peixes, corais, plantas aquáticas etc.), que é mais difícil de ser notado, há o impacto na paisagem, com mudanças na coloração da água e odores desagradáveis, descarga de substâncias tóxicas e não degradáveis etc. (BRASIL, 2007, p.50).

Outro fator agravante de poluição ao meio ambiente, decorre da implantação da fossa séptica, que ainda é bastante utilizada pela população que reside em volta das lagoas e o esgoto é despejado diretamente na água, diante da ausência do saneamento básico, conforme depoimentos: 
Infelizmente não existe saneamento (Ricardo, 43);

Em fossas sépticas já que não tem o saneamento (Paula, 23; Alice, 26 e Vilma, 35);

Há fossa, mas tem esgoto jogado direto no mar... Na altura de Barreta você pode ver como o esgoto cai no mar (Pedro, 66).

Diante dos relatos obtidos é necessário conjugar ações efetivas para que a atividade turística realizada nas lagoas não resulte em mais poluição, tanto para os residentes, quanto para os turistas. Nesse contexto, Arruda (2010) apontou em sua pesquisa a ausência do saneamento básico nas três lagoas, a água utilizada pelos estabelecimentos comerciais é obtida de poços artesianos sem qualquer tratamento para o consumo e para o esgotamento.

\section{Relação da Lagoa com o Turismo}

Rota dos Nativos responde à demanda de dispersão de atrativos turísticos concentrados em Natal para produção de espaços em outros municípios, como Nísia Floresta, Tibau do Sul e a própria interiorização.

Quando questionados sobre o que seria turismo, muitos dos entrevistados afirmaram que o turismo consiste no deslocamento de uma localidade para outra para obter o descanso e o lazer. Nos seguintes depoimentos constatam-se o conhecimento dos entrevistados sobre Turismo:

Turismo é o ato de se viajar para algum lugar para descansar e conhecer novos costumes e pessoas (Paula, 23);

São as pessoas que viajam nas férias para conhecer as coisas ou ver amigos e família de outro canto (Alice, 26);

Aproveitar os recursos naturais e os desenvolvidos pelo homem, como forma de lazer e apreciação (Felipe, 27).

Os depoimentos de Claudia (32 anos) e Ricardo (43 anos) demonstram a importância do turismo para a comunidade, como parte essencial do seu sustento. Mantendo o princípio básico do turismo como gerador de emprego e renda.

Então, o turismo é quando vem gente de fora para ver o que é nosso. Compra as coisas, e conhecer [...]. Como quando vem uma pessoa de fora e almoça aqui com a família. Para mim isso é turismo (Claudia, 32);

Visitas de pessoas de diversos lugares que vem prestigiar as belezas e atrativos locais (Vilma, 35);

Meus clientes são turistas, na maioria, são pessoas que vem atrás de ver outras coisas além do que estão acostumadas. Atrás de uma novidade (Ricardo, 43).

A localização do município e das sete lagoas pode ser observada no mapa (Figura 7). 


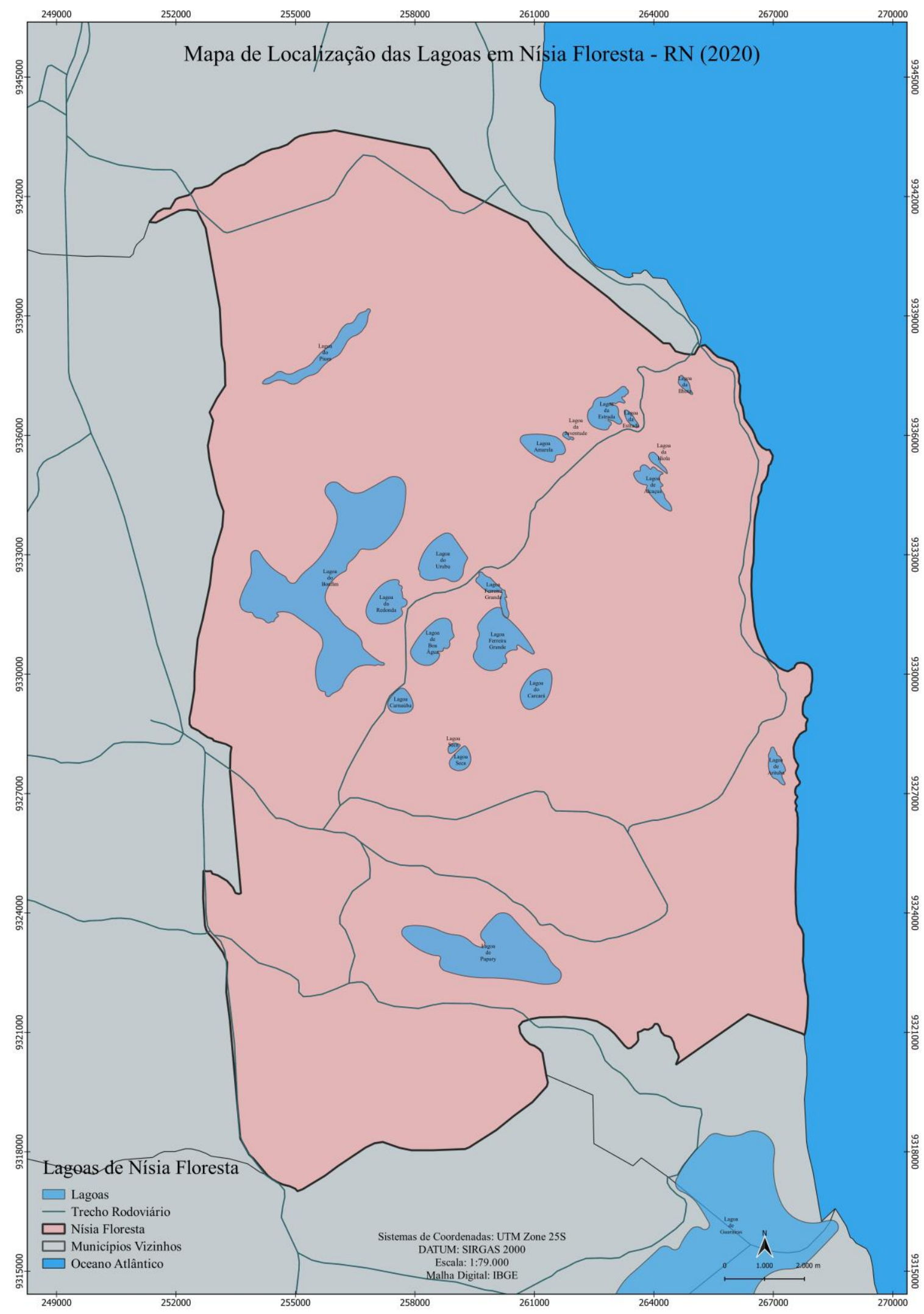

Figura 7: Mapa de Localização das Lagoas em Nísia Floresta/RN (2020). Figure 7: Location Map of Lagoons in Nísia Floresta/RN (2020).

Fonte: Elaborado pelos autores (2020).

Source: Elaborated by the authors (2020). 
Os recursos naturais são um dos mais importantes atrativos que motivam o excursionismo de lazer ou da experiência ao ar livre contrastante aos dias da semana. No entanto, provoca um consumo efêmero e superficial que impossibilita a experiência mais aprofundada e empírica: "Tendo em vista que temos muitas belezas naturais que geram curiosidade dos turistas (Paula, 23); A lagoa faz o turismo acontecer, porque muita gente vem atrás da lagoa para descansar [...]" (Claudia, 32). De acordo com Dias (2005) existe uma apreensão com os impactos que o turismo pode ocasionar, justificado pela desordem com a qual ele cresce e se desenvolve.

Os achados reiteram o impacto ambiental do turismo de um dia ou excursionismo registrado na pesquisa de Arruda (2010). Ele ressalta: O impacto ambiental é perceptível com o amontoado de lixo, cercas e muros da comunidade local. A poluição definida por Almeida (2013) como sendo a degradação da qualidade natural de um recurso, causando assim o malestar social e a desconfiguração do cenário:

Existem muitos desses turistas que geram degradação ao espaço. Eles não pensam que aqui é a casa de outra pessoa e tratam como se não importasse muito (Paula, 23);

Ao mesmo tempo em que o turismo gera melhoria econômica, quando trabalhado de modo errado danifica nosso ambiente (Felipe, 27); O povo só polui tudo, joga lixo e depois vai embora (Pedro, 66).

Os depoimentos na sequência mostram a relevância econômica do turismo para a comunidade, mas confirmam possíveis impactos ambientais. Dentre as causas que acometem o meio ambiente, ocorre o reconhecimento da má administração da atividade como negligência que propicia à degradação.

Parte de nossa economia vem do turismo (Paula, 23);

Com o turismo consigo vender minhas coisas, quando vem muita gente de fora sempre ganho um pouco mais (Alice, 26);

É muito importante culturalmente e economicamente, mas tudo tem seu viés positivo e negativo (Felipe, 27);

Trabalho com a lagoa e ela chama muita gente de fora, ela me dá o meu trabalho [...]. Sem o trabalho não tenho como sustentar minha família (Cláudia, 32).

A fala de Vilma (35 anos), idealiza o turismo, que além da visibilidade do lugar é o aumento da oportunidade de emprego e movimento da economia. Esse achado está de acordo com a literatura que aponta o turismo enquanto elemento gerador de bem-estar, renda e inclusão socioeconômica em comunidades receptoras, caracterizando-se, assim, por ser uma ferramenta da política de desenvolvimento (GRECHI, 2011; PASA GÓMEZ et al., 2016; SANSOLO; BURSZTYN, 2009). 
O turismo traz muitos benefícios, se administrados de forma correta dentro do controle ambiental e investimento para tal. Ocorrendo assim aumentam as oportunidades de empregos e renda para o município (Vilma, 35);

O turismo permite que eu mantenha as portas abertas e me dá condições de pagar as contas, muita gente aqui vive do turismo. Ou porque tem restaurante, ou casa de praia (Ricardo, 43);

De certa forma leva ao crescimento da cidade (Gabriela, 51).

Muitos dos depoimentos mostram-se esperançosos com relação ao futuro, alguns dos entrevistados acreditam que a falta de apoio é um dos impasses das riquezas naturais locais. Como observamos nos depoimentos a seguir.

Em Nísia Floresta existe muito a ser descoberto ainda, e se o povo conseguir apoio para fazer isso, acho que a nossa comunidade vai ganhar muito (Alice, 26);

Espero que melhore muito com o tempo, que tenha muito emprego e a lagoa fique cheia de peixe (Cláudia, 32);

Como um lugar muito turístico, que cresce cada vez mais (Gabriela, 51).

A gestão pública é mencionada como insatisfatória ou problemática. Segundo Oliveira, Melo e Dantas (2017, p. 332) "o Estado, tendo noção do potencial socioeconômico da atividade turística, muda a sua forma de atuação e deixa de ser somente um agente regulador, passando a demandar políticas públicas para intervir na atividade”. As políticas públicas direcionadas para o turismo, de forma geral, têm sido orientadas para a gestão dos municípios e das regiões com o intuito de descentralizar os processos de tomada de decisões sobre o desenvolvimento turístico (FRATUCCI; SCHWANTES; MAIA, 2014).

[...] uma política pública de turismo faz-se necessária para gerenciar conflitos, promover atividades, regenerar áreas degradadas e desenvolver novos usos alternativos. Esse ponto é, no entanto, ainda discutível, uma vez que as tendências nas últimas décadas foram a crescente desregulamentação do setor (autorregulação da "indústria" pelo mercado) e a ênfase nas parcerias público-privadas, especialmente na construção de infraestrutura (OLIVEIRA; MELO; DANTAS, 2017, p. 334).

A capacidade de articulação, acesso à informação e transparência, mobilização e conscientização, tem levado algumas comunidades a uma 
participação maior na gestão dos seus municípios, elencando o turismo como uma alternativa de desenvolvimento através da geração de emprego e renda. Em contrapartida, a descontinuidade, falta de capacidade técnica, entraves burocráticos, falta de integração entre os órgãos oficiais de turismo e conflitos de interesses geram um grande entrave das políticas públicas para o setor (MATIAS; CARVALHO; SOUSA, 2016).

Matias, Carvalho e Sousa (2016), afirmam ainda que "uma gestão pública deficiente, inerte, desprovida de comprometimento, acarreta danos em longo prazo muito nocivos a uma comunidade". Em geral, as falas retratam descrença com o sistema e com o cenário futuro. $O$ depoimento que melhor representa a indignação da comunidade com a gestão é o de Vilma (35 anos) que, segunda ela, se aflige com a "politicagem" do sistema.

Do jeito que o poder público vem deixando a desejar, principalmente com respeito à segurança, não dá para esperar muita mudança positiva. É triste ver nosso lar se perdendo em tanta desgraça, espero de verdade que as coisas melhorem (Paula, 23);

Impróprio para uso, visto o descaso que tá hoje (Felipe, 27);

O que vejo hoje são fachadas para politicagem. Estradas intrafegáveis [...]. É um abandono total. Há cinco anos vai depender do próximo gestor Municipal, se for como o atual, vejo pioras. Se assumir alguém que entenda e enxergue a importância do turismo, a nossa cidade com certeza estaria extremamente evoluída em todos os setores (Vilma, 35);

Acho que não muda muita coisa não, é pouco tempo pra dizer, mas se fosse pensar daqui a 20 anos a natureza estará bem degradada, do jeito que anda agora com cada um pensando só no seu e não em preservar (Ricardo, 43); Se continuar assim não será muito bom não (Pedro, 66).

O relato de Ricardo (43 anos) reforça que o tempo é crucial para a mudança, que o processo é de natureza complexa e demanda tempo, ao envolver várias instâncias. A eficácia do planejamento turístico sustentável depende do comprometimento com a preservação/conservação do meio ambiente por parte de instâncias locais, regionais e nacionais. No contexto ecológico, "o turismo tem o potencial de colaborar com a proteção e a conservação do meio ambiente, e também com a consequente melhoria e manutenção da qualidade de vida das comunidades receptoras" (BRASIL, 2007, p.46).

\section{Impacto ambiental e a produção de espaço turístico}

A atividade turística pode ocasionar diversos impactos ambientais. De acordo com Fandé e Pereira (2014), esse exercício da atividade turística provoca impactos ambientais positivos e negativos, que envolvem 0 ambiente natural, o ambiente transformado e 0 ambiente sociocultural. 
Contudo, o ambiente natural é o mais vulnerável aos impactos ambientais negativos do turismo.

A série Roteiros do Brasil também aborda os impactos ambientais que o turismo provoca em ambientes naturais e destaca a produção de lixo como um resultado negativo do turismo. Segundo a obra, a poluição pode ocorrer em todas as suas formas, como a emissão de gases nocivos a camada de ozônio, o lançamento de óleo na água; poluição sonora pela utilização de aparelhos de som e, sobretudo, o excesso de produção e destinação inadequada do lixo, que na maioria das vezes é encaminhado para lixões a céu aberto (BRASIL, 2007).

Nesse contexto, Arruda (2010, p.71) destaca em sua pesquisa, que o serviço de coleta de resíduos sólidos é "bastante precário, pois não atende às necessidades das lagoas, cabendo aos comerciantes realizar a manutenção da limpeza do lugar". Outro aspecto importante apontado por Arruda (2010) decorre da produção de lixo pelos próprios turistas, segundo o autor:

[...] é importante ressaltar que não existe muita diferença quanto à degradação ambiental causada pelo lixo deixado pelos excursionistas farofeiros e pela existência entre as fossas sépticas das barracas instaladas na margem das lagoas as quais se apresentam como um fator de risco, eminente, de poluição ambiental (ARRUDA, 2010, p.99).

Conforme exposto no tópico "Saneamento básico e coleta seletiva" desta pesquisa, tanto a utilização das fossas sépticas, quanto o descarte do esgoto nas lagoas é uma realidade entre os moradores do entorno delas. $O$ crescente uso das lagoas para atividade turística sem qualquer planejamento coloca em risco esses ecossistemas, comprometendo sua conservação.

Nesse sentido, Lanzer et al. (2013) pontua que é iminente a necessidade de gestão pública em elaborar um zoneamento para as lagoas, delimitando áreas prioritárias para conservação e áreas destinadas à atividade turística, de veraneio e comércio. Mesmo a atividade turística ocorrendo através do excursionismo de um dia, há uma emergente demanda por um planejamento adequado e controlado do acesso à água.

Da década 1990 até os dias atuais, na área de estudo, os resultados de políticas públicas para o desenvolvimento do turismo, dotou de infraestrutura urbana, os acessos viários, fluxo turísticos de municípios da região metropolitana de Natal, da Paraíba e do Pernambuco. Por outro lado, Arruda (2010), constatou em Arituba a presença de 36 ônibus excursionistas em um único feriado ocorrido em 2010. Na Lagoa do Carcará há relatos da presença de 60 ônibus de excursionistas em um único feriado, totalizando 3 mil excursionistas para explorar uma pequena faixa de terra na lagoa.

Percebe-se então, a necessidade de maior engajamento da gestão municipal, através da implantação e execução dos serviços essenciais, 
como a coleta de lixo e a ampliação e/ou adequação da infraestrutura. De acordo com a série Roteiros do Brasil, tais melhorias fazem parte dos impactos positivos do turismo:

\begin{abstract}
Melhoria das condições ambientais do destino, aliada à melhoria da infraestrutura básica da localidade, como os sistemas de saneamento, de transporte (estradas de acesso etc.), de comunicações, de saúde, paisagismo da área urbana (praças, calçadões etc.), trazendo benefícios para a população local (BRASIL, 2007, p.47).
\end{abstract}

Outro aspecto importante abordado por Arruda (2010) refere-se à produção de espaço turístico. Segundo o autor, o mercado é formado por agentes sociais, que estão em situação de escalas local e regional e, por vezes, tomam para si a hegemonia do processo de produção do espaço, para assegurar a consecução de seus interesses. Todavia, ao tratar da produção do espaço turístico, deve-se levar em consideração a existência de agentes não-hegemônicos e neste caso, o papel dos turistas não pode ser negligenciado, sendo, portanto, indispensável reconhecer sua relevância na produção do espaço (ARRUDA, 2010).

Todavia, desenvolver estratégias de Educação Ambiental e turística, considerando as tomadas de soluções propostas por Rudzewicz et al. (2011), após diagnosticarem a situação dos recursos hídricos das lagoas no Sul, adotaram ferramentas para sensibilização e valorização dos ecossistemas costeiros por meio da disseminação do conhecimento. Eles concluíram que as mudanças de atitude no uso da água e a gestão sustentável das águas superficiais e subterrâneas estão atreladas à Educação Ambiental como tema transversal.

A educação turística e ambiental envolve aspectos da conscientização e sensibilização sobre aspectos cruciais de preservar mananciais para a segurança alimentar da comunidade, de sedentarização animal e preservação da paisagem. Para Leff (2009), o desenvolvimento sustentável requer mudança nos valores de cada indivíduo que compõem a sociedade, mas existem antes da responsabilidade social, outras demandas relacionadas à Educação Ambiental e à indução do consumo pela globalização.

Nesta pesquisa, a percepção dos guias sobre os impactos ambientais e a sustentabilidade do meio ambiente aparecem nos seguintes depoimentos:

Sim, durante trilhas de ecoturismo, há estímulo à preservação do meio ambiente, conscientização de recolhimento do lixo, de não retirar mudas e não caçar animais silvestres, além de não transitar em lugares de reconstrução florestal. Parise (26 anos). 
A guia de turismo Parise (26 anos) declarou que a "sustentabilidade é associada a conservação de um sistema, que nesse caso seria conservação do atrativo natural, que é a lagoa". Para Wilson (31 anos) "sustentável é a combinação de utilização responsável dos recursos naturais e humanos para garantir que as gerações futuras tenham a mesma oportunidade de usufruir delas".

O depoimento dos guias está de acordo com um dos impactos positivos do turismo expostos na série Roteiros do Brasil, segundo a qual, a sensibilização dos turistas para as questões ambientais, amplia sua percepção da realidade e contribui para conservação e proteção do ambiente visitado, assim a responsabilidade é compartilhada. Quanto aos demais agentes envolvidos, como o poder público local, a iniciativa privada, a sociedade civil e o terceiro setor, a percepção de que a competitividade do destino está diretamente ligada à sua qualidade ambiental pode também contribuir em mudanças de postura em relação aos cuidados com o meio ambiente (BRASIL, 2007).

\section{Considerações Finais}

O fato de existir pouca água doce na superfície terrestre é uma das condições que implicam estratégias para o uso racional da água doce, privilegiando o consumo e realizando o planejamento ambiental e turístico adequado para viabilizar a interiorização do Turismo.

As práticas excursionistas de turismo de um dia na Rota dos Nativos nas lagoas do município de Nísia Floresta geram uma grande preocupação em relação papel da gestão pública no planejamento ambiental e turístico desse cenário.

A Rota dos Nativos é uma alternativa de descentralização do Turismo de Natal, contudo constata-se que a falta de infraestrutura e de controle da capacidade de carga pode degradar o ambiente natural, com resíduos sólidos e outros impactos decorrentes das práticas excursionistas de um dia. A poluição ambiental compromete a paisagem para a hospitalidade, caso o turismo sustentável não seja planejado em tempo hábil. Atividades de educação e conscientização ambiental devem ser implementadas no sentido de preservar os mananciais de água doce.

A atividade turística é entendida como de vital importância para as comunidades do entorno das lagoas e desenvolvimento do município, porém é necessário atentar-se para o planejamento e gestão destas localidades para que questões de proteção ambiental e a participação da comunidade não sejam negligenciadas. A participação da comunidade no planejamento da atividade turística pode favorecer a conservação das paisagens e delimitar o uso sustentável do espaço lacustre destinado ao turismo.

No plano político que rege a gestão pública para a tomada de decisão de questões ambientais, os processos são norteados pela lógica econômica que se beneficia de entraves burocráticos intersetoriais. A ineficiência da comunicação e operacionalização é a motriz para toda a sorte 
de especulação e exploração desordenada de recursos naturais que comprometem seriamente a qualidade dos recursos hídricos.

Reitera-se a urgência de implementar um modelo de planejamento e gestão direcionado especificamente para o turismo, interligando questões de âmbito econômico, social, político e ambiental, com aplicação de medidas eficazes para mitigar os impactos negativos na área e preservar as peculiaridades da região lacustre.

\section{Referências}

ALMEIDA, J. C. Avaliação do Índice de Qualidade da Água na Lagoa dos Patos. Trabalho de Conclusão de Curso (Engenharia Ambiental e Sanitária). Universidade Federal de Pelotas. Pelotas, RS, 2013.

ARRUDA, A.P. Os farofeiros em excursão nas Lagoas de Arituba, Boágua e Carcará (Nísia Floresta/RN). Análise de uma outra face do Turismo Potiguar. Dissertação de Mestrado. Universidade Federal do Rio Grande do Norte, UFRN, 2010.

AMADO, F. A. Te. Direito ambiental esquematizado: Rio de Janeiro/São Paulo: Forense/ Método, 2016.

BACCI, D. de La C.; PATACA, E. M. Educação para a água. Estudos Avançados. v. 22, n. 63, 2008, p.211-226.

BRASIL. Lei no 6.938, de 31 de agosto de 1981. Dispõe sobre a Política Nacional do Meio Ambiente, seus fins e mecanismos de formulação e aplicação, e dá outras providências. Brasília: Legislação Federal, 1981.

BRASIL. Constituição (1988). Constituição da República Federativa do Brasil de 1988. Brasília, DF: Presidência da República, 1988. Disponível em:

<https://www.senado.leg.br/atividade/const/con1988/con1988 05.10.1988/C ON1988.asp>. Acesso em: 05 nov. 2017.

BRASIL. Ministério do Turismo. Introdução à Regionalização do Turismo - Roteiros do Brasil: Programa de Regionalização do Turismo. Brasília, Ministério do Turismo, 2007.

BRASIL. Ministério do Turismo. Prodetur. Brasília: Ministério do Turismo, 2015.

BRASIL. Ministério das Cidades. Secretaria Nacional de Saneamento Ambiental - SNAS. Sistema Nacional de Informações sobre Saneamento - SNIS: Diagnóstico dos Serviços de Água e Esgotos - 2015. Brasília: SNSA/MCIDADES, 2017.

CASTRO, J.E. A água ainda não é uma mercadoria: Aportes para o debate sobre a mercantilização da água. Rev. UFMG, Belo Horizonte, v. 20, n.2, p. 190-221, 2013.

DEEN, T. A água não pode faltar na RIO + 20. São Paulo: Carta Capital, 2012. 
DENCKER, A. F. M. Pesquisa em Turismo: Planejamento, Métodos e Técnicas. São Paulo: Futura, 2007.

DIAS, R. Introdução ao turismo. São Paulo: Atlas, 2005.

DIAS, R. Turismo sustentável e meio ambiente. São Paulo: Atlas, 2008.

DUMAZEDIER, J. Lazer e cultura popular. São Paulo: Perspectiva, 1973.

FABER, M. A importância dos rios para as primeiras civilizações. Rio Grande do Sul: História llustrada, v. 2. 2011.

FANDÉ, M. B.; PEREIRA, V. F. G. C. Impactos ambientais do turismo: um estudo sobre a percepção de moradores e turistas no Município de ParatyRJ. Revista Eletrônica em Gestão, Educação e Tecnologia Ambiental. v. 18, n. 3, Set-Dez 2014, p.1170-1178.

FERREIRA, R. C.; LOPES, W. G. R.; ARAÚJO, J. L. L. A água como suporte para atividades de lazer e turismo: possibilidades e limitações da barragem Piracuruca no estado do Piauí (Brasil). RA'E GA. n. 25, 2012, p. 134-163.

FRATUCCI, A.C.; SCHWANTES, G.X.L.; MAIA, Y.C. Estrutura da gestão pública do turismo nos municípios do estado do Rio de Janeiro. Revista de Cultura e Turismo, Ilheús, v. 1, n. 8, p. 140-159, fev. 2014.

GOMES, C. L. Estudos do lazer e geopolítica do conhecimento. Revista Licere. Belo Horizonte, v.14, n.3, p.1-25, set./2011.

GRECHI, D. O desenvolvimento turístico sob a ótica da economia institucional: uma análise do caso de Bonito (MS). 2011. Tese (Programa de Pós-graduação em Economia - Doutorado) - Universidade Federal do Rio Grande do Sul, UFRGS, Porto Alegre, 2011.

KUHNEN, A. Meio ambiente e vulnerabilidade: a percepção ambiental de risco e o comportamento humano. Londrina: Geografia, v. 18, n. 2, p. 37-52, 2009.

LANZER, R.M.; CASTRO RAMOS, B.V.; MARCHETT, C.A. Impactos ambientais do turismo em lagoas costeiras do Rio Grande do Sul. Caderno Virtual de Turismo, v. 13, n. 1, 2013.

LEFF, E. Saber Ambiental: Sustentabilidade, Racionalidade, Complexidade, Poder. São Paulo: Vozes, 2009.

MATIAS, E. M.; CARVALHO, A. V.; SOUSA, P. G. Gestão pública em São Miguel do Gostoso (RN): em estudo de caso. In: Seminário da ANPTUR, 13, 2016, São Paulo. Anais... São Paulo, 2016, p. 1-16.

MAY, T. Pesquisa social: Questões, métodos e processos. Porto Alegre: Artmed, 2001.

MEKSENAS, P. Pesquisa social e ação pedagógica: conceitos, métodos e práticas. São Paulo: Loyola, 2002.

MMA, Ministério do Meio Ambiente. Proteção da qualidade e do abastecimento dos recursos hídricos: aplicação de critérios integrados no desenvolvimento, manejo e uso dos recursos hídricos. Conferência das 
Nações Unidas sobre Meio Ambiente e Desenvolvimento. Agenda 21, Capítulo 18. Brasília: Ministério do Meio Ambiente, 1992.

MMA, Ministério do Meio Ambiente. Coleta seletiva. Brasília: Ministério do Meio Ambiente, 2016.

MOLINA, S. O pós-turismo. São Paulo: Aleph, 2003.

OLIVEIRA, P. H. C. N.; MELO, A. C. L.; DANTAS, A. V. S. Gestão e desenvolvimento turístico em Natal: uma análise histórica da consolidação da secretaria e das políticas públicas. In: ENCONTRO NACIONAL DE ENSINO E PESQUISA DO CAMPO DE PÚBLICAS (ENEPCP), 3, 2017, Brasília. Anais... Brasília, 2017. v. 2. p. 331-346.

ONUBR- Nações Unidas do Brasil. ODS6 - Água Potável e Saneamento: Assegurar a disponibilidade e gestão sustentável da água e saneamento para todos e todas. Brasília: Nações Unidas Brasil, 2015.

PASA GÓMEZ, C.; FALCÃO, M.C.; CHEREM, L., SILVA, T.N. A participação da comunidade no turismo de base comunitária: um estudo de múltiplos casos. Caderno Virtual de Turismo, v. 16, n. 2, p. 263-279, 2016.

RIBEIRO, L. G. G.; ROLIM, N. D. Planeta água de quem e para quem: uma análise da água doce como direito fundamental e sua valoração mercadológica. Revista Direito Ambiental e sociedade. v. 7, n. 1, 2017, p. 7-33.

RUDZEWICZ, L.; LANZER, R.M. SCHÄFER, E.A. Potencialidades do ecoturismo no litoral médio e sul do Rio Grande do Sul. Anais do VIII Congresso Nacional de Ecoturismo e do IV Encontro Interdisciplinar de Ecoturismo em Unidades de Conservação. Revista Brasileira de Ecoturismo, São Paulo, v.4, n.4, 2011, p. 531.

SANSOLO, D. G.; BURSZTYN, I. Turismo de base comunitária: Potencialidade no espaço rural brasileiro. In: BARTHOLO, R.; SANSOLO, D. G.; BURSZTYN, I. (Org.). Turismo de base comunitária: diversidade de olhares e experiências brasileiras. Rio de Janeiro: Letra e Imagem, 2009. p. 142-161.

SILVA, D. C. Electrorremediação de solos contaminados com metais pesados. Dissertação (Mestrado em Química). Coimbra: Universidade de Coimbra, 2015.

SPERLING, M. V. Introdução à qualidade das águas e ao tratamento de esgotos: princípios do tratamento biológico de águas residuárias. Belo Horizonte: Editora da Universidade Federal de Minas Gerais, 2005.

TAVARES, A.M. City tour. São Paulo: Aleph, 2002.

UNIC. Direito à água potável e saneamento básico e juridicamente vinculativo, afirma Conselho de Direitos Humanos. Rio de Janeiro: Centro de Informações das Nações Unidas, 2010. 
Sueli Aparecida Moreira: Universidade Federal Rural do Rio de Janeiro, Seropédica, RJ, Brasil.

E-mail: suelimoreira@yahoo.com.br

Link para o currículo Lattes: http://lattes.cnpq.br/9469781068838287

Ingrid Rosalina da Silva: Universidade Federal do Rio Grande do Norte, Natal, RN, Brasil.

E-mail: <ingrid-rosalina@outlook.com>

Link para o currículo Lattes: http://lattes.cnpq.br/9937915424213715

Camila Kayssa Targino Dutra: Universidade Estadual do Rio Grande do Norte, Natal, RN, Brasil.

E-mail: camila_targino2010@hotmail.com

Link para o currículo Lattes: http://lattes.cnpq.br/9872037081151736

Silvânia Melo da Cunha: Universidade Federal do Rio Grande do Norte, Natal, RN, Brasil.

E-mail: silvaniamelo0508@gmail.com

Link para o currículo Lattes: http://lattes.cnpq.br/9958317186143829

Gilberto Correia dos Santos: Universidade Federal de São Paulo, São Paulo, SP, Brasil.

E-mail: gilbertocorreiadossantos1969@gmail.com

Link para o currículo Lattes: http://lattes.cnpq.br/5563998143054143

Bruno Ferreira Nunes Sobrinho: Universidade Federal do Rio Grande do Norte, Natal, RN, Brasil.

E-mail: bceroulas@gmail.com

Link para o currículo Lattes: http://lattes.cnpq.br/3072739848747751

Guilherme Bridi: Universidade Federal do Rio Grande do Norte, Natal, RN, Brasil.

E-mail: guime70@gmail.com

Link para o currículo Lattes: http://lattes.cnpq.br/1626859396401842

Data de submissão: 28 de julho de 2020

Data de recebimento de correções: 26 de dezembro de 2021

Data do aceite: 26 de dezembro de 2021

Avaliado anonimamente 